\title{
Telomere-Mediated Genomic Instability and the Clinico-Pathological Parameters in Breast Cancer
}

\author{
Anuradha Poonepalli, ' Birendranath Banerjee,' Kalpana Ramnarayanan, ${ }^{2}$ Nallasivam Palanisamy, ${ }^{2,3}$ \\ Thomas Choudary Putti, ${ }^{4}$ and M. Prakash Hande ${ }^{1 *}$ \\ 'Department of Physiology, Yong Loo Lin School of Medicine, National University of Singapore, Singapore \\ ${ }^{2}$ Department of Cancer Biology and Pharmacology, Genome Institute of Singapore, Genome, Singapore \\ ${ }_{3}^{3}$ Michigan Center for Translation Pathology, University of Michigan Health System, Comprehensive Cancer Center, Ann Arbor, MI \\ ${ }^{4}$ Department of Pathology, Yong Loo Lin School of Medicine, National University Singapore, Singapore
}

A study was undertaken to correlate telomere dysfunction and genomic instability with the histopathological grades and the estrogen and progesterone receptor status in breast cancer. Sixty-one archived breast tissues (38 cancer tissues and 23 paired normal tissues) were used in the study. The breast tumor tissues showed significantly shorter telomeres (7.7 kb) compared with the paired adjacent tissues $(9.0 \mathrm{~kb})$ by Southern blot analysis. Moreover, telomere shortening was more significant in Grade III tumors than in the Grade II tumors $(P=0.05)$. Quantitative fluorescence in situ hybridization on paraffin tissue sections revealed a similar trend in telomere shortening. Telomere attrition was associated with telomere dysfunction as revealed by the presence of significantly higher anaphase bridges in tumor cells which was tumor grade dependent. Furthermore, estrogen receptive negative tumors displayed higher anaphase and internuclear bridges. Selected samples from each grade showed greater genomic imbalances in the higher grades than the lower grade tumors as detected by array-comparative genomic hybridization. Telomerase activity was found to be higher in the higher grades (Grade II and III) compared with the lower grade (Grade I). The average mRNA expression of TRFI and POTI was lower in the tumor tissues than in the normal tissues. Tankyrase I mRNA expression showed a grade-dependent increase in tumor tissues and its expression was also high in estrogen and progesterone negative tumors. The data support the notion that telomere dysfunction might be of value as a marker of aggressiveness of the tumors in breast cancer patients. (1) 2008 Wiley-Liss, Inc.

\section{INTRODUCTION}

Breast cancer is the most common cause of cancer deaths among women worldwide (Chia et al., 2002). Suitable biomarkers are necessary for assessment of the tumors and proper clinical treatment decisions. Tumor/nodes/metastases stages have long been used as the most powerful indicators of breast cancer prognosis and recurrence (Hayes et al., 2001). In addition, a number of other markers like tumor type and grade, hormonal receptor status, markers of proliferation, cell death, micrometastasis, and neovascularization provide additional information about the prognosis, response to treatments, and recurrence (Hayes et al., 2001). Increasing number of markers is being developed to understand the disease prognosis and determine the treatment options.

Genomic instability is an important factor in cancer initiation and progression (Hanahan and Weinberg, 2000; Meeker and Argani, 2004). Telomeres and the associated telomeric proteins play significant roles in maintaining the integrity of the genome. Loss of telomere function is one of the mechanisms underlying genomic instability. Telo- mere loss or dysfunction results in complex types of genomic abnormalities, including loss of heterozygosity, gene amplifications, deletions, and aneuploidy (Lo et al., 2002; Murnane and Sabatier, 2004; Sabatier et al., 2005). Furthermore, the consequential genomic instability has also been shown to be associated with aggressiveness and poor prognosis of tumors (Kronenwett et al., 2006). In carcinomas, histomorphologically increasing gradation of dysplasia is associated with the aggressiveness of the tumors. Hence, it is important and interesting to understand the association of telomere dysfunction with the aggressiveness of the tumors.

The regulation of telomere length is a dynamic process involving telomerase and a highly complex

Supported by: National Medical Research Council (NMRC), Ministry of Health, Singapore; Grant number: NMRC/0910/2004; Grant number: WBS number 185-000-088-213.

* Correspondence to: M. Prakash Hande, PhD, Genome Stability Laboratory, Department of Physiology, Yong Loo Lin School of Medicine, National University of Singapore, Block MD9, 2 Medical

Drive, Singapore 117597. E-mail: phsmph@nus.edu.sg

Received 2 April 2008; Accepted 7 July 2008

DOI 10.1002/gcc.20608

Published online 21 August 2008 in

Wiley InterScience (www.interscience.wiley.com). 
system involving a number of telomere-associated proteins. Telomere repeat binding factor 1 (TRF1), protection of telomeres 1 (POT1), and Tankyrase 1 (TRF1-interacting ankyrin-related ADP ribose polymerase) are telomere-associated proteins that are part of telomere structure and have essential roles in telomere length regulation (Liu et al., 2004a). TRF1 binds to TTAGGG double stranded repeats of telomeres and has been identified as a negative regulator (Bilaud et al., 1996, 1997; Broccoli et al., 1997). Tankyrase 1 interacts with TRF1 and its over expression was shown to release TRF1 from the telomeres and induce telomere elongation. Tankyrase 1 has thus been shown as a positive regulator of telomere length (Smith et al., 1998). POT1 is recruited to the $3^{\prime}$ single-stranded portion of the telomeric DNA and it was found to employ telomerase for telomere elongation (Liu et al., 2004a,b; Smogorzewska and de Lange, 2004).

The aim of this study was to investigate the association of telomere dysfunction and genomic instability with the tumor prognostic factors like histopathological grades and hormonal receptor status. In addition, the mRNA expression of selected telomere related genes such as TRF1, Tankyrase 1, and POT1 were also studied.

\section{MATERIALS AND METHODS}

\section{Patient Samples}

Archived human invasive ductal breast carcinoma with the paired adjacent tissues or DNA and RNA samples $(n=61$; Tumor $=38$; Paired normal $=23$ ) were obtained from the Department of Pathology, National University Hospital, Singapore. This study was approved by National University of Singapore-Institutional Review Board (NUS-IRB; NUS-062). The samples were histopathologically graded based on the modified ScarffBloom-Richardson grading system. Estrogen receptor (ER) and progesterone receptor (PR) status of the tumor samples were also determined.

\section{Telomere Restriction Fragment Length Analysis}

Genomic DNA was isolated from the frozen tissues using QIAamp Tissue Kit (Qiagen, Valencia, CA). Telomere length was assessed by measuring the telomere restriction fragments using the Telo TTAGGG telomere length assay kit (Roche Diagnostics, Indianpolis, USA) by following manufacturer's instructions. After digestion of the genomic DNA with HinfI and RSAI, they were separated on a $0.8 \%$ agarose gel. The DNA was then transferred onto the nylon membrane (Roche Diagnostics, Indianpolis, USA) by Southern blotting and the blotted DNA fragments were hybridized to digoxigenin-labeled probe specific for telomeric repeats and incubated with a digoxigenin-specific antibody covalently coupled to alkaline phosphate. Finally, the immobilized telomere probe was visualized by metabolizing CDP-Star, a highly sensitive chemiluminescence substrate. The average TRF length was determined by comparing the signals to a molecular weight standard using the Kodak Molecular Imaging Software (Kodak, Rochester, USA).

\section{Peptide Nucleic Acid-Fluorescence In Situ Hybridization for Telomeres on Tissue Sections}

Paraffin embedded tissue sections of 4- $\mu$ m thickness were deparaffinized in $100 \%$ Xylene. After dehydrating with $100 \%$ ethanol, the slides were incubated in $1 \mathrm{M}$ sodium thiocyanate at $80^{\circ} \mathrm{C}$ for 8 min. Slides were incubated in $1 \%$ pepsin in $0.01 \mathrm{M}$ $\mathrm{HCl}$ for $2 \mathrm{~min}$ at $37^{\circ} \mathrm{C}$ and dipped through the ethanol series and air dried. The tissue sections were then hybridized with Cy3 conjugated PNA telomere probe (Applied Biosystems, Boston, MA) for $2 \mathrm{hr}$ at room temperature after co-denaturation at $80^{\circ} \mathrm{C}$ for $3 \mathrm{~min}$ (Hande et al., 1999). Stringent washes were performed and the slides were counterstained with DAPI $(0.1 \mu \mathrm{g} / \mathrm{ml})$. Images were captured with Zeiss Axioplan 2 imaging microscope (Carl Zeiss, Gottingen, Germany) and the telomere signals were quantitated using the ISIS software (Metasystems, Altusseheim, Germany).

\section{Telomerase Activity}

The TRAPeze ${ }^{\circledR}$ XL Telomerase Detection Kit (Chemicon International, Temecula, CA) was used according to the manufacturer's instructions to measure the telomerase enzyme activity of breast cancer tissues and the paired adjacent tissues. The breast tissue extract was prepared after homogenizing the cells and resuspending in $100 \mu$ of CHAPS XL Lysis Buffer (included in the telomerase detection kit) and incubating on ice for $30 \mathrm{~min}$. The extract was pelleted $\left(12,000 \mathrm{~g}\right.$ at $\left.4^{\circ} \mathrm{C}\right)$, and the supernatant was frozen at $-80^{\circ} \mathrm{C}$ until assayed for telomerase. The TRAPeze ${ }^{\circledR}$ XL Telomerase Detection Kit uses a modified TRAP (telomerase repeat amplification protocol) assay to detect telomerase activity through the amplification of telomeric repeats using fluorescence energy transfer primers (Amplifluor ${ }^{\mathrm{TM}}$ ) that produce measurable fluorescence only when incorporated into TRAP products. The fluorescence of each reaction was measured with a Magellan fluorescent plate reader. 
Telomerase activity of each sample was determined by calculating the ratio of the increase in fluorescein absorbance (produced by the amplification of telomeric repeats) divided by the increase in sulforhodamine absorbance.

\section{Anaphase Bridges and Internuclear Bridges}

Anaphase bridges are chromosomal bridges that are not resolved during anaphase and are associated with telomere dysfunction and chromosome end fusions (Meeker and Argani, 2004; Jin et al., 2007; Stewenius et al., 2007). The frequency of anaphase bridges is commonly used as an indicator of telomere-mediated chromosomal instability. H\&E stained paraffin sections were used to score the anaphase and internuclear bridges. Fifty mitotic cells were scored for anaphase bridges and 500 nuclei were scored for internuclear bridges.

\section{Array Comparative Genomic Hybridization (Array-CGH) on Tissue Samples}

Genomic DNA was extracted from the tissues by phenol-chloroform method. Normal female DNA (Promega, Madison, WI) was used as the control DNA. DNA was run on a $1.2 \%$ agarose gel to check for any degradation or RNA contamination and was quantitated by NanoDrop ND-1000 UV-vis spectrophotometer. Array-CGH (aCGH) was performed according to the protocol suggested by Agilent Technologies, Santa Clara, USA. Genomic DNA was amplified using the Qiagen REPLI-g mini kit (Qiagen, Valencia, CA). The amplified genomic DNA was digested by $A l u \mathrm{I}$ (Promega, Madison, WI) and RsaI (Promega, Madison, WI) on a $37^{\circ} \mathrm{C}$ circulating water bath for $2 \mathrm{hr}$ and transferred onto ice. The amplified digested genomic DNA was cleaned up using QIAprep Spin Miniprep Kit (Qiagen, Valencia, CA). DNA was further quantitated using the NanoDrop ND-1000 UV-vis Spectrophotometer. It was then fluorescently labeled using random primers (supplied with Agilent Genomic DNA labeling kit PLUS) with Cyanine 3-dUTP (test) and Cyanine 5-dUTP (control). The labeled genomic DNA was cleaned using the Microcon YM-30 filters. Cy3-labeled and Cy5-labeled genomic DNA were mixed with

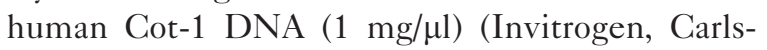
bad, USA), Agilent 10x blocking agent and Agilent $2 \mathrm{x}$ hybridization buffer. The hybridization sample mixture was applied to the gasket slide and then the active side of the microarray slide was placed on top of the gasket slide to form a "sandwich slide pair." The SureHyb chamber cover was placed onto the sandwiched slides and the slide clamp was assembled onto both pieces. The assembled slide was then placed in the rotator rack in a hybridization oven at $65^{\circ} \mathrm{C}$ to rotate at $20 \mathrm{rpm}$ and left to hybridize at $65^{\circ} \mathrm{C}$ for $40 \mathrm{hr}$. The slides were disassembled in Oligo aCGH Wash Buffer 1 and washed in Oligo aCGH Wash Buffer 1 at room temperature for $5 \mathrm{~min}$ and in Oligo aCGH Wash Buffer 2 at $37^{\circ} \mathrm{C}$ for $1 \mathrm{~min}$. The slides were scanned immediately to minimize the impact of environmental oxidants on signal intensities using Agilent scanner that was set to scan area $(61 \times 21.6$ $\mathrm{mm}^{2}$ ). Scan resolution was set to 10 using dye channel red and green. Green and red photomultiplier tubes were set to $100 \%$. Data analysis was done using the $\mathrm{CGH}$ analytics software.

\section{Quantitative Real-Time PCR}

RNA was extracted from the frozen tissues by TRIZOL method and quantitated by the nanodrop spectrophotometer. The analyses of the TRF1, Tankyrase 1, and POT1 mRNA expression were performed using the Light Cycler RNA Master SYBR Green Kit (Roche Diagnostics, Indianapolis) by real-time quantitative RT-PCR. The primer sequences for the genes are as follows: TRF1 forward primer, $5^{\prime}$-gca aca ggg cag agg cta tta $\mathrm{tt}-3^{\prime}$; TRF1 reverse primer, $5^{\prime}$-agg get gat tcc aag ggt gta $-3^{\prime}$, Tankyrase 1 forward primer, $5^{\prime}$-atg ccc cca gag gcc tta-3'; Tankyrase 1 reverse primer, $5^{\prime}$-ggt gga tgc tgg tga gat ca- $3^{\prime}$ and POT1 forward primer, $5^{\prime}$-tca gtc tgt taa ctt cat tgc $\mathrm{cc}-3^{\prime}$; POT1 reverse primer, $5^{\prime}$-tgc acc atc ctg aaa aat tat atc- $3^{\prime}$ (First base). The house keeping gene $18 \mathrm{~S}$ rRNA was used to normalize the sample-to-sample variation in the amount of the input RNA, and also to evaluate the quality of the isolated RNA and RT efficiency. Amplification of the $18 \mathrm{~S}$ rRNA was performed using the following primers: forward primer: $5^{\prime}$ gta acc cgt tga acc cca tt- $3^{\prime}$ and reverse primer: $5^{\prime}$ cca tcc aat cgg tag tag cg $3^{\prime}$. PCRs were performed in a LightCycler $^{\circledR}$ instrument (Roche Diagnostics) as follows: reverse transcription at $61^{\circ} \mathrm{C}$ for $20 \mathrm{~min}$, initial denaturation at $95^{\circ} \mathrm{C}$ for $2 \mathrm{~min}$; amplification for 45 cycles of denaturation $\left(95^{\circ} \mathrm{C}, 5 \mathrm{sec}\right.$, ramp rate $2^{\circ} \mathrm{C} / \mathrm{sec}$ ), annealing (optimal temperature, 5 sec, ramp rate $\left.2^{\circ} \mathrm{C} / \mathrm{sec}\right)$ and extension $\left(72^{\circ} \mathrm{C}\right.$, product length $[\mathrm{bp}] / 25 \mathrm{sec}$, ramp rate $\left.2^{\circ} \mathrm{C} / \mathrm{sec}\right)$. The standard curve was constructed with 10 -fold serial dilutions of the RNA which corresponded to the total RNA ranging from 0 to $500 \mathrm{ng}$. The PCR reaction for amplification was performed using 500 $\mathrm{ng}$ of the total RNA for the target genes and $5 \mathrm{ng}$ for the house keeping gene. All of the measurements included the determination of the standards 
and no-template as a negative control, in which water was substituted for the RNA. Data for TRF1 mRNA, POT1 mRNA and Tankyrase 1 mRNA were normalized to the data for $18 \mathrm{~s}$ RNA. The products were run on a $1 \%$ agarose gel to confirm the size of the final product for all of the genes.

\section{Statistical Analyses}

Statistical analyses of the data were done by unequal variance $t$ test (Welch test) using Microsoft Excel 2007 (Microsoft Corporation, Redmond, USA) (Ruxton, 2006).

\section{RESULTS}

\section{Significantly Greater Telomere Shortening in the Higher Grades of Breast Cancer Samples}

Paired adjacent tissues were found to have longer TRFs (Mean $\pm \mathrm{SD}$ and range: $9.0 \pm 2 \mathrm{~kb}$ and $6.8-13.2 \mathrm{~kb})$ than in the breast tumor tissues (Mean \pm SD and range: $7.7 \pm 0.63 \mathrm{~kb}$ and $6.7-10$ $\mathrm{kb})$. The difference in length was statistically significant $(P<0.05)$ (Fig. 1A). The average percentage decrease was more significant in Grade III tumors $(P<0.05)$ than in the Grade II tumors $(P=0.05)$ (Fig. 1A). To gain further insights into the telomere length changes, we have used in situ analysis of telomere length by quantitative-fluorescence in situ hybridization on paraffin tissue. Quantitative-fluorescence in situ hybridization analysis yielded similar reductions in telomere lengths in tumor tissues compared with the adjacent tissues (Fig. 1B).

\section{Higher Telomerase Activity in Breast Cancer Samples than in the Adjacent Tissues}

Telomere dysfunction results from critically short telomeres or the loss of stability of the telomere secondary structure. The telomere length is a balance between its loss due to the cell proliferation and the maintenance by telomerase. Hence, we decided to look at the status of telomerase in relation to the aggressiveness of the tumors. Telomerase activity was detected in all the cancerous tissues, and it was about 1.5 times more in the higher grades (Grade II and III) than the lower grade (Grade I) tumors (Fig. 1C). We have also detected low levels of telomerase activity in about $66 \%$ of the paired adjacent tissues; however, this was about 20 times lower than that detected in the cancerous tissues. There was no correlation between the telomerase activity and other clinico- pathological parameters such as hormonal receptor status, lymph node status, or the HER2/neu status (Data not shown).

\section{Telomere Attrition Associated with Elevated Chromosome Instability in the Higher Grades}

To determine whether the telomere shortening observed in the higher grade tumors was associated with telomere dysfunction, the percentage of anaphase bridge formation was analyzed. Telomere shortening may compromise the integrity of chromosome ends and lead to the formation of dicentrics and rings. These abnormal structures may form bridges at anaphase that either break or initiate a series of breakage-fusion-bridge events. Thus, anaphase bridges are chromatin bridges in between separating chromosome masses during anaphase, which may result in gene amplification or loss when breaking (Lengauer, 2001). Anaphase bridge formation is a correlate of telomere dysfunction (Meeker and Argani, 2004; McPherson et al., 2006; Jin et al., 2007; Stewenius et al., 2007). There was a fivefold increase in the frequency of anaphase bridges in Grade III from Grade I $(P<0.05)$ in breast tumor samples (Fig. 2A). Internuclear bridges that are also indicative of chromosomal instability showed a threefold increase in frequency from Grade I to grade III $(P<0.01)$ and twofold from Grade I to Grade II $(P<0.05)$ (Fig. 2B) breast cancers. Thus, telomere shortening was correlated with telomere dysfunction which was concurrent with the histological grading. Telomere dysfunction in the form of anaphase bridges also correlated with the estrogen receptor status where the frequency was higher in ER-negative tumors (Table 1). ER status has also been associated with the prognosis of breast cancers with ER- negative tumors having worse prognosis than ER-positive tumors. However, the increased percentage of anaphase bridges in PR-negative compared to PR-positive tumors was not statistically significant.

\section{Increased Genomic Imbalances in the Form of Amplifications or Deletions in Higher Grades of Breast Cancer by aCGH}

Telomere-mediated chromosome rearrangements cause genomic imbalances, which were measured by aCGH. We used selected samples (six samples; two from each grade) to measure genomic imbalances by aCGH. Our results showed greater genomic imbalances in the form of deletions and amplifications in the higher grade tumors compared with the lower grade tumors (Figs. 3A 
A

Grade I Grade II Grade III
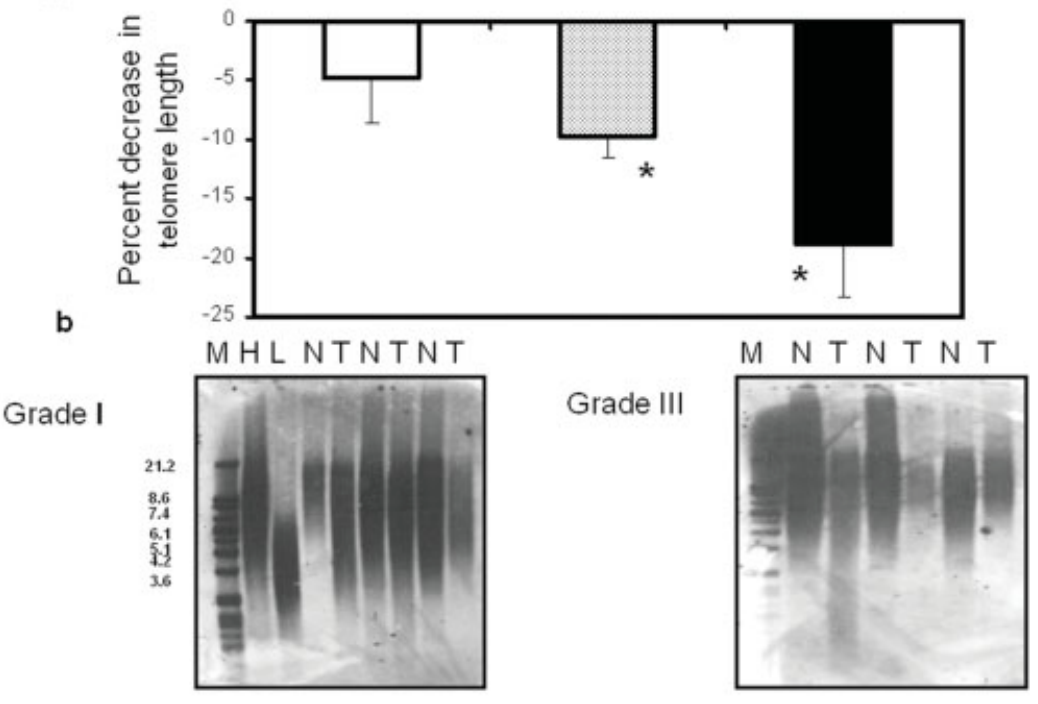

B

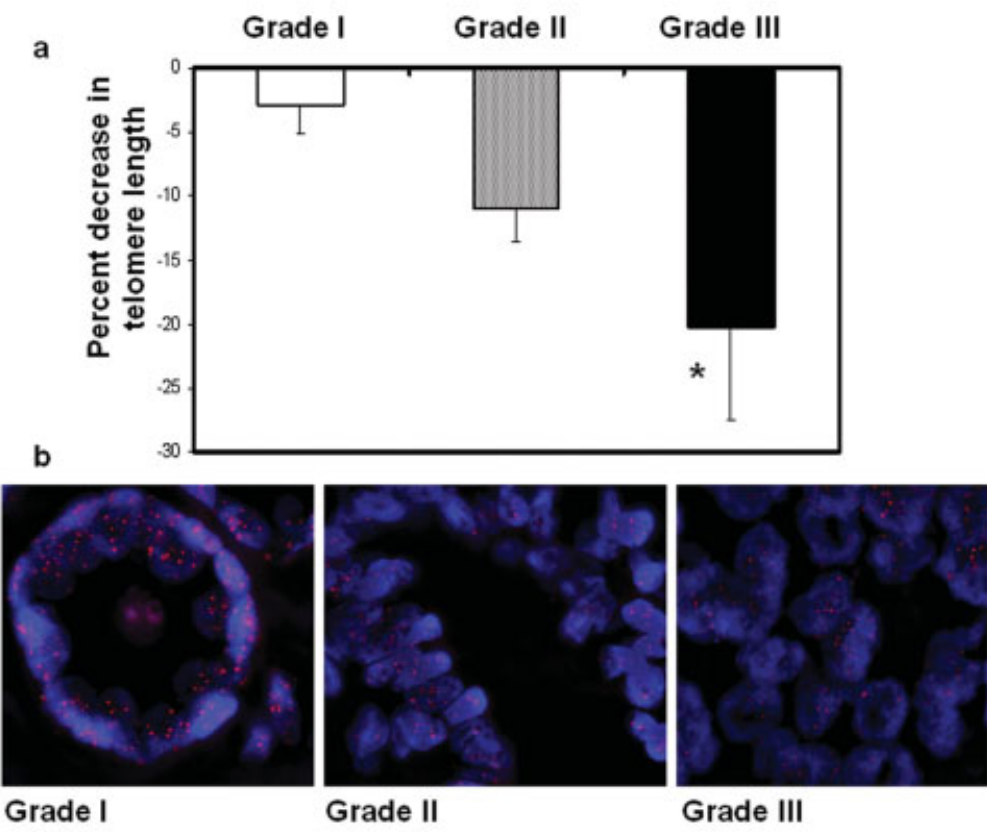

C

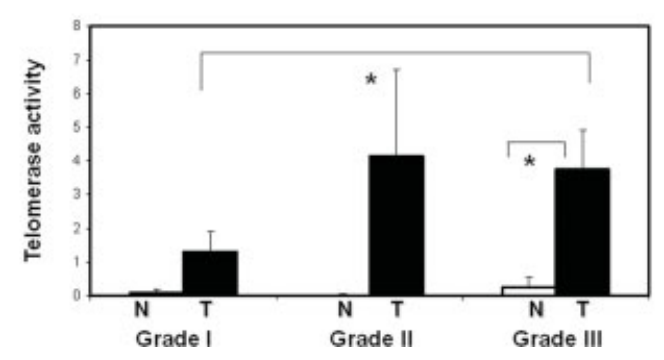

Figure I. Average percent decrease in telomere length in different grades of tumors. A: (a) Telomere length measured by Southern blotting of the terminal restriction fragments. Grade I tumors showed $4.76 \%$ decrease, Grade II tumors showed $9.76 \%$ decrease, and Grade III tumors showed $18.86 \%$ decrease in telomere length on an average when compared with the paired adjacent tissues. $* p<0.05$. (b) Representative samples of telomere length analysis by Southern blotting for Grade I and Grade III tumors are shown here. N, normal; T, tumor; L, control low; H, control high; M, marker. Bars indicate SE. B: (a) Telomere length measured on paraffin tissue sections by PNA FISH. Grade I tumors showed $2.8 \%$ decrease, Grade II tumors showed $9.9 \%$ decrease, and Grade III tumors showed $16.86 \%$ decrease in telomere length on an average when compared with the paired adjacent tissues. Bars indicate SE. (b) Representative pictures of tissue FISH in the paraffin sections of Grade I, II, and III tumors showing telomere signals using the telomere specific $\mathrm{Cy}-3$ labeled PNA probe. $* P<0.05$. C: Average telomerase activity ( $\Delta$ Fluorescein/ $\Delta$ Sulforhodamine) in the breast cancer tissues and the paired adjacent tissues. The solid bars are the cancer tissue samples and the white bars are the paired adjacent tissue samples. Bars indicate SE. ${ }^{*} P<0.05$. 
A

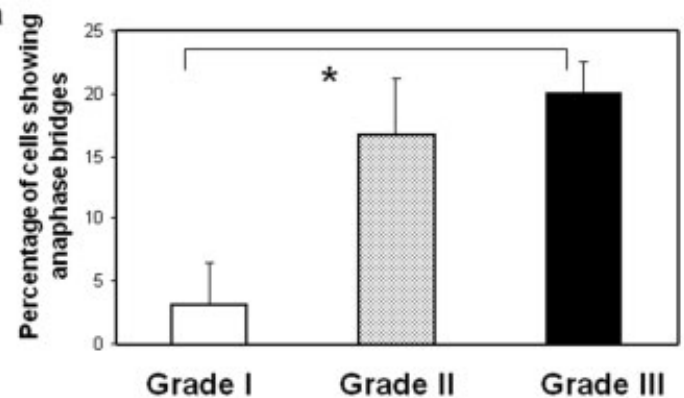

b
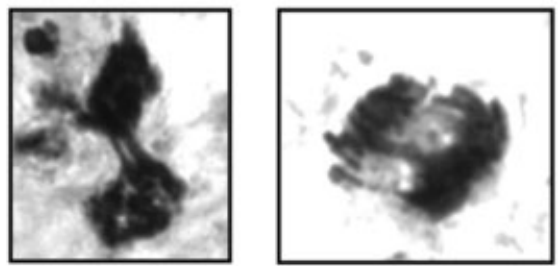

Figure 2. Anaphase bridges as an indicator of telomere dysfunction. A: (a) Average percentage of anaphase bridge formation in all of the three grades of tumors. Grade I tumors had 3.3\%, Grade II 16.6\%, and Grade III $20.7 \%$ of anaphase bridges. $* P<0.05$. (b) Anaphase bridges in Haematoxylin and eosin (H\&E) stained tumor paraffin sections. B: (a)
B a

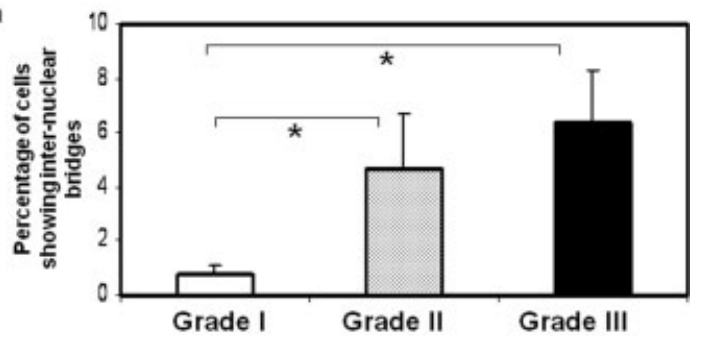

b

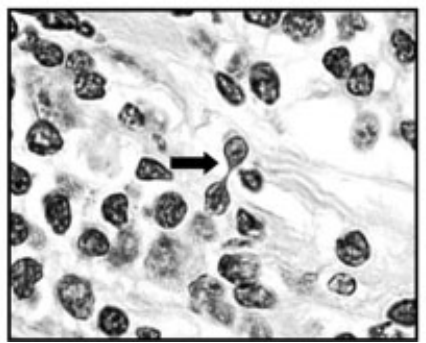

Average percentage of internuclear bridges in all of the three grades of tumors. Grade I tumors had 0.7\%, Grade II 4.75\%, and Grade III 6.32\% of internuclear bridges. $* P<0.01$. (b) Internuclear bridge in Haematoxylin and eosin (H\&E) stained tumor paraffin sections. Results are shown in percentage $\pm \mathrm{SE}$.

TABLE I. Correlation of Telomere Length, Telomere Dysfunction and Expression of Telomere Related Genes with Clinicopathological Parameters

\begin{tabular}{|c|c|c|c|c|c|}
\hline & $\begin{array}{l}\text { Percent telomere } \\
\text { shortening }\end{array}$ & $\begin{array}{l}\text { Percent anaphase } \\
\text { bridges }\end{array}$ & $\begin{array}{c}\text { TRFI } \\
\text { expression }\end{array}$ & $\begin{array}{l}\text { Tankyrase I } \\
\text { expression }^{\mathrm{a}}\end{array}$ & $\begin{array}{c}\text { POTI } \\
\text { expression }^{\mathrm{a}}\end{array}$ \\
\hline \multicolumn{6}{|c|}{ Histological grades } \\
\hline Grade I & 4.77 & 3.22 & 0.00011 & $1.8 \mathrm{E}-088$ & 0.46 \\
\hline Grade II & $12.99^{\mathrm{b}}$ & $16.67^{c}$ & 0.00018 & $3.1 \mathrm{E}-08^{\mathrm{C}}$ & 0.02 \\
\hline Grade III & $19.19^{c}$ & $20.03^{c}$ & 0.00017 & $1.9 \mathrm{E}-07$ & 0.24 \\
\hline \multicolumn{6}{|c|}{ Oestrogen receptor (ER) status } \\
\hline Negative & 14.78 & $20.95^{\mathrm{d}}$ & $0.00014^{d}$ & $2.4 \mathrm{E}-07^{\mathrm{d}}$ & 0.34 \\
\hline Positive & 12.14 & 12.67 & 0.00032 & $3.1 \mathrm{E}-08$ & 0.12 \\
\hline \multicolumn{6}{|c|}{ Progesterone receptor (PR) status } \\
\hline Negative & 16.14 & 19.86 & 0.00022 & $2.2 \mathrm{E}-07^{\mathrm{e}}$ & 0.26 \\
\hline Positive & 9.62 & 13.05 & 0.00021 & $3.1 \mathrm{E}-08$ & 0.15 \\
\hline \multicolumn{6}{|c|}{ Lymph node metastasis } \\
\hline Absent & 13.06 & 16.30 & 0.00021 & $9.8 \mathrm{E}-08$ & 0.33 \\
\hline Present & 14.46 & 18.10 & 0.00024 & 2. $1 \mathrm{E}-07$ & 0.29 \\
\hline \multicolumn{6}{|c|}{ Tumour size } \\
\hline$<2 \mathrm{~cm}$ & 9.27 & 23.65 & 0.00048 & $3.1 \mathrm{E}-08$ & 0.30 \\
\hline$\geq 2 \mathrm{~cm}$ & 14.15 & 16.20 & 0.00019 & $1.5 \mathrm{E}-07$ & 0.31 \\
\hline
\end{tabular}

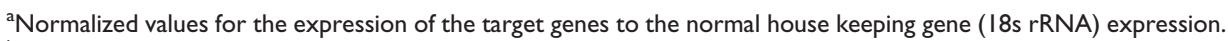

${ }^{\mathrm{b}} \mathrm{P}=0.05$ (compared with paired adjacent tissue samples).

${ }^{c} P<0.05$ (compared with paired adjacent tissue samples).

${ }^{\mathrm{d}} P<0.05$ (compared with ER positive samples).

${ }^{\mathrm{e}} \mathrm{P}<0.05$ (compared with PR positive samples).

and $3 \mathrm{~B})$. Studies are in progress to determine the nature of these genes in breast tumors.

Differential Expression of mRNA for TRFI, POTI, and TANKYRASE $I$ in Relation to the Histological Grades of the Tumors

As mentioned earlier, in addition to telomerase, a number of telomere associated proteins have been shown to play a role in maintaining telomere integrity. We looked at the mRNA expression of some of the positive and negative regulators of telomere length. TRF1 showed a heterogeneous pattern of expression in the samples. However, on average, the expression of TRF1 mRNA was higher in adjacent tissues compared with the tumor tissues. On the other hand, when compared between 


\section{A GradeI}
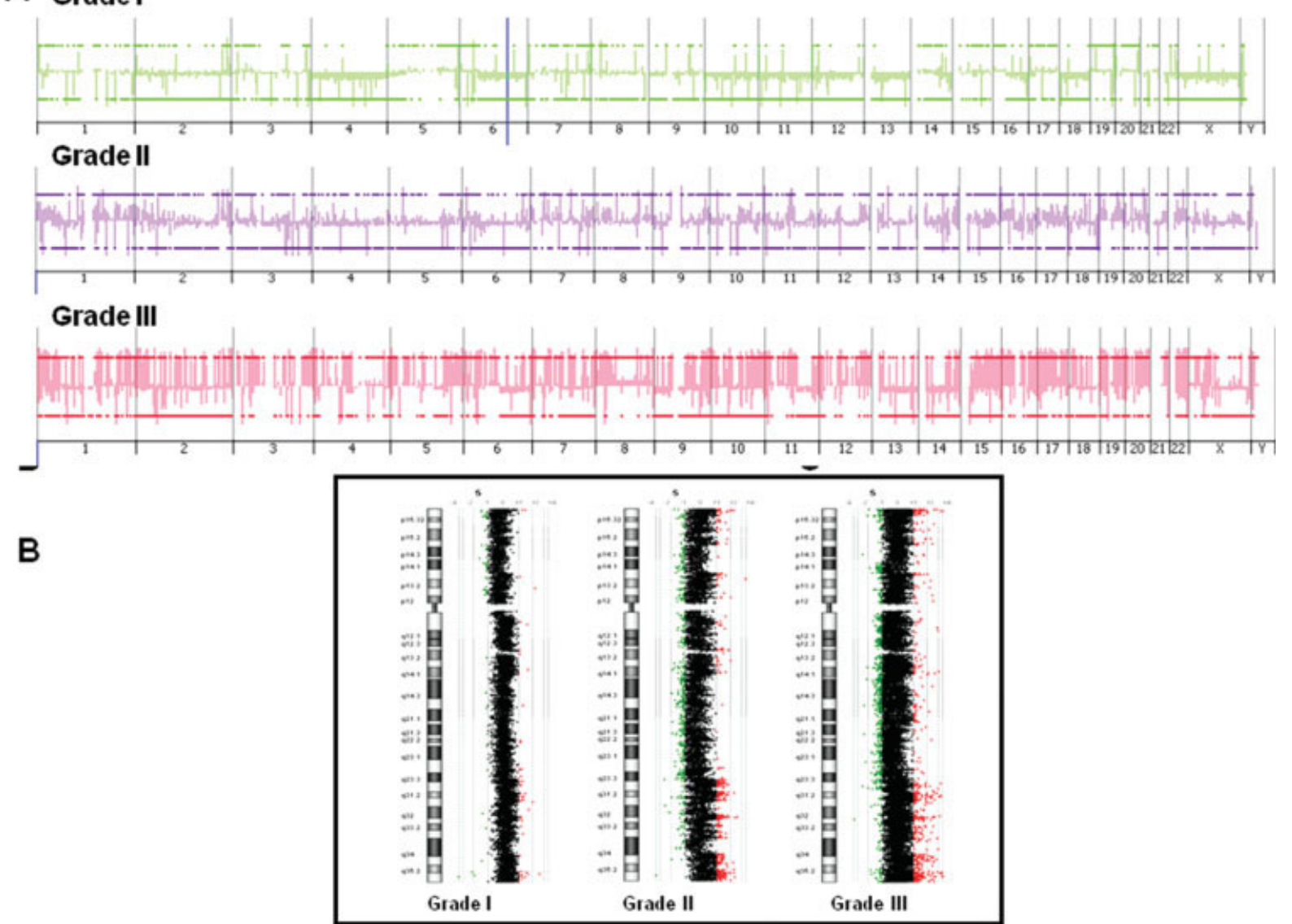

Figure 3. Array-CGH analysis in breast tumor samples. A: Complete genome view by array-CGH showing greater genomic instability in the higher grade than the lower grade of tumors. $\log _{2}+1.0$ horizontal scale bars (above which is considered amplification) and $\log _{2}-1.0$ horizontal scale bars (below which is considered deletions) are included

grades the TRF1 expression did not show a significant trend, but was higher in the lower grades than the higher grades (Fig. 4A and Table 1). Average expression of POT1 mRNA appears to be downregulated in cancer tissues. The expression was observed to be higher, but not statistically significant $P>0.05$ ), in the early grade (Grade I) compared with the latter grades (Grade II and III) (Fig. 4B). Tankyrase $1 \mathrm{mRNA}$ expression was significantly higher in cancerous tissues compared with the adjacent tissues. There was also an increase in the mRNA expression from lower grades to higher grades (Fig. 4C and Table 1). Its expression was also high in ER- and PR-negative tumors (Table 1).

\section{DISCUSSION}

Breast cancer patients are often classified into those with favorable (well-differentiated tumors) or less favorable (poorly-differentiated tumors) out-

for reference. B: Chromosome 5 used as a representative chromosome shows greater genomic imbalances in the higher grades than the lower grades. Green dots represent deletions and red dots represent amplifications.

come using prognostic markers. Histopathological grading is widely accepted and a good prognostic indicator of breast cancer and prospectively used in the clinical treatment decisions (Dalton et al., 2000; Ellsworth et al., 2008). The cells in Grade I tumors resemble normal cells and appear to grow and multiply slowly, whereas higher grade tumors grow rapidly and are poorly differentiated. Genetically unstable tumors have been shown to be larger in size and to be at higher grade compared with the stable tumors (Christov et al., 1989; Kronenwett et al., 2006). Genomic instability contributes to a major problem in management of breast cancer phenotypes because of their more aggressive phenotype and chemo-resistance (Loeb, 2001; Chin et al., 2004).

Telomere dysfunction may be one of the molecular causes of genomic instability. We have reported the telomere dysfunction phenotype in BRCA1-deficient cells suggesting the fact that loss 

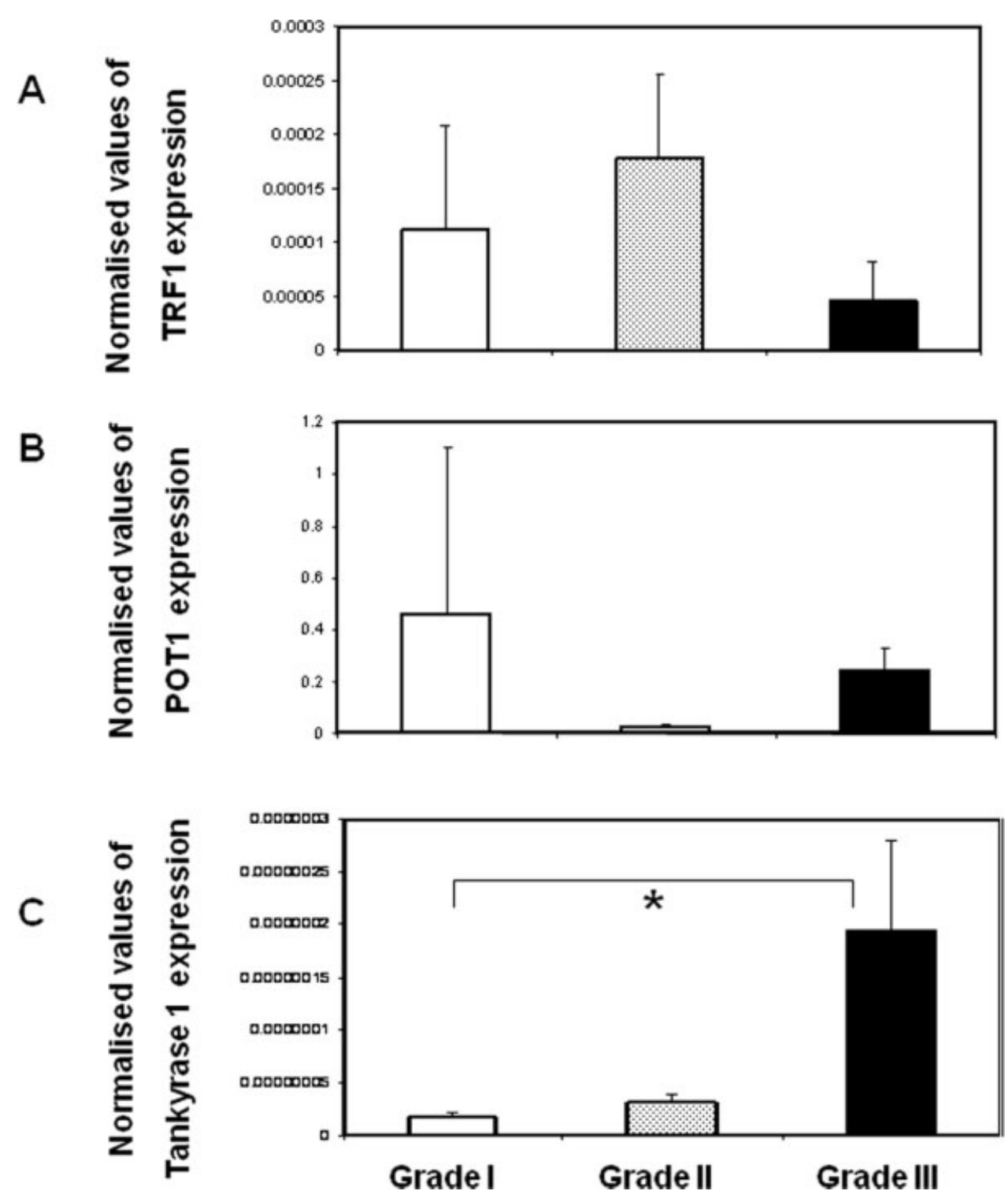

Figure 4. Differential mRNA expression of telomere associated proteins by real time RT-PCR. The values on the $y$-axis are normalized to the $18 \mathrm{~s}$ rRNA expression. A: TRFI mRNA expression in comparison between grades of tumor tissues. B: POTI mRNA expression in comparison between grades of tumor tissues. C: Tankyrase I mRNA expression in comparison between grades of tumor tissues. $* P<0.01$.

of telomere integrity might contribute to chromosome end dysfunction and permit the formation of potentially oncogenic translocations (McPherson et al., 2006). Breast cancer patients exhibited significant chromosome instability and telomere loss following radiotherapy, which suggests that there is marked increase in telomere dysfunction in breast cancer patients (Banerjee et al., 2008). Recent studies in bladder cancer (Jin et al., 2007) and Wilms' tumor (Stewenius et al., 2007) demonstrated telomere shortening and telomere dysfunction in higher grade tumors. Evidence from our study support the hypothesis that telomere dys- function impairs chromosomal stability and is associated with the aggressiveness of the tumors. The breast cancer cells have infinite replicative potential and they replicate at a much faster rate than the normal human cells (Bignold, 2007). Therefore, it is reasonable to assume that the rate of telomere loss is higher in the breast cancer cells compared with normal human cells, thereby leading to more rapid telomere shortening in the breast cancer cells.

Earlier studies examined the telomere length in breast cancer by terminal restriction fragment analysis in Southern blotting (Odagiri et al., 1994; 
Rha et al., 1999). But these studies showed inconclusive results regarding associations with clinicopathological features like grading, hormonal receptor status, etc. It is also reported that telomere shortening in breast carcinomas are associated with histological grading (Odagiri et al., 1994) and increased genomic instability and metastasis (Griffith et al., 1999). Telomere shortening was also correlated with poor prognosis in several types of cancer (Griffith et al., 1999). O'Hagan et al., (2002) demonstrated that telomere dysfunction is a major cause of chromosome instability using aCGH. They examined chromosomal gains and losses in mTerc ${ }^{-1-} \operatorname{trp}_{53} 3^{+-}$mice and found that telomere dysfunction results in segmental gains and losses that drive epithelial carcinogenesis in the mouse model (O'Hagan et al., 2002) similar to that ones seen in human epithelial tumors. This study supports the hypothesis that telomere-based crisis and associated breakage-fusion-bridge cycles drive chromosomal instability in cancer cells (Raptis and Bapat, 2006).

Breast cancer is assumed to progress as a linear model with poorly-differentiated (Grade III) breast tumors would developing from moderately- (Grade II) and well-differentiated (Grade I) tumors. Earlier studies have shown that allelic imbalances were greater in the higher grades compared to the lower grades (Ellsworth et al., 2008). Our data by aCGH supports this observation. However, the majority of the observed genetic alterations were not identical among different grades with only few common genetic modifications.

Genetically unstable breast cancers have also been associated more frequently with ER- and PRreceptor negative breast cancers (Kronenwett et al., 2006). Breast cancer patients with tumors that are ER-positive and/or PR-positive have lower risks of mortality and better prognosis after their diagnosis compared with women with ER-negative and/or PR-negative disease (Dunnwald et al., 2007). In the present study, higher telomere dysfunction was observed in ER-negative tumors supporting the complex nature of such tumors (Table 1).

It is known that telomerase is activated by tumor cells to ensure survival of the cancer cells with genomic instability (Campisi et al., 2001). Some studies have shown the association of telomerase activity with tumor type, nodal metastasis (Roos et al., 1998; Mokbel et al., 1999), high cellular proliferation (Mokbel et al., 1999), large tumor size, and lymphovascular invasion in invasive breast cancer (Bednarek et al., 1997; Roos et al., 1998;
Mokbel et al., 2000). For the first time, as far as we are aware of, the present study has shown greater telomerase activity in the higher grades (Grades II and III) of breast cancers than the lower grade (Grade I). One earlier study has shown that higher grades of tumors have more telomerase positive cells detected in the form of increased hTERT expression (Kirkpatrick et al., 2003a). Greater telomere shortening in the higher grades could be an effect of rapid proliferation compared with the slowly proliferating lower grade tumors. Higher telomere loss in the higher grades may probably initiate a feedback mechanism to increase the telomerase activity compared with the lower grades. Accordingly, the cells in the higher grades showed increased telomerase activity than the lower grades in our study. Moreover, there may be a selection pressure for telomerase-positive cells in the higher grades allowing the telomerase positive cells bypass the restriction of proliferation common in cells with critically short telomeres (Clark et al., 1997). Additionally, we found detectable telomerase activity in the adjacent apparently normal tissues indicating that they are not completely noncancerous. In earlier studies, hTERT expression was seen in the adjacent tissues (Kirkpatrick et al., 2003b; Hines et al., 2005). Adjacent tissues could be in the initial stages of malignant transformation since telomerase reactivation has been shown as an early event in breast carcinogenesis (Shpitz et al., 1999). This proposition is supported by our data that the telomerase activity in the adjacent tissues also followed a similar trend as the cancerous tissues. The tissues adjacent to the aggressive Grade III tumors showed greater telomerase activity than the less aggressive Grade I tumors. The aggressive cells in higher grades probably have greater tissue invasion and infiltration resulting in spill over of cancerous cells into the adjacent tissues and hence the detectable telomerase activity. On the other hand, it may also indicate initiation of tumorigenesis in these tissues.

TRF1 is known to protect telomeres and inhibit telomere replication. Thus, the decreased TRF1 probably facilitates the access of telomerase to telomeres. There was nonsignificant decrease in the levels of TRF1 in the malignant tissues in our study which is in agreement with earlier studies (Saito et al., 2002; Salhab et al., 2008). Furthermore, the decreased TRF1 mRNA expression in the higher grades accompanied by telomere shortening suggests a possible transcriptional suppression of TRF1 to release telomerase from negative regulation. It has been shown that nuclear over- 


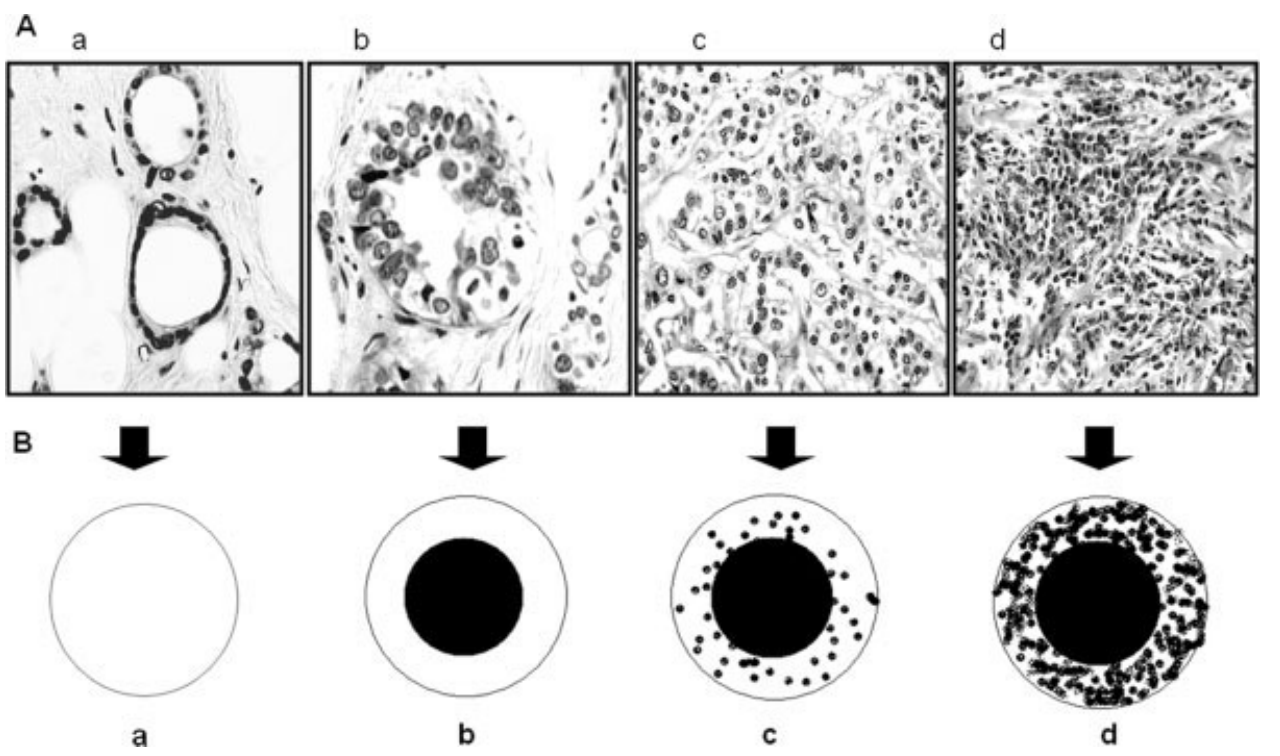

Figure 5. A: Haematoxylin and eosin stained paraffin of normal and tumor tissues showing different histological grades. (a) Normal, (b) Grade I, (c) Grade II, (d) Grade III. B: Schematic representation of tumor (solid black) with surgical cut margins and the normal area (white) with possible infiltration of cancer cells into the adjacent normal tissues in Grade I, Grade II, and Grade III tumors.

expression of Tankyrase 1 leads to poly(ADP-ribosyl) ation of TRF1 and loss of TRF1 with consequential increased telomerase access and telomere elongation (Donigian and de Lange, 2007). Consistent with the reports by Gelmini et al. (2004), we observed significantly higher levels of Tankyrase 1 in advanced tumors. Furthermore, for the first time we report a correlation of Tankyrase 1 expression to the histopathological grades where there is a grade dependent increase in Tankyrase 1. The increased expression of Tankyrase 1 and decreased expression of TRF1 in higher grades act in synergism at the telomeres and have a prominent role in tumor progression and aggressiveness.

Presence of telomerase activity and grade dependent expression of telomere-related genes (data not shown) in the tissues adjacent to the malignant tissues reiterates our proposition that the apparently normal tissues next to the malignant tissues may not be completely normal. We speculate that surgical resection margins, which may appear histologically normal might harbor potentially neoplastic cells, possibly through infiltration of tumor cells into the adjacent tissues beyond the surgical cut margin (Fig. 5). There are many incidences of recurrence of cancer after lumpectomy in the adjacent tissues previously thought to be histologically normal. Adjacent mammary epithelium might not have been completely removed during lumpectomy for invasive carcinoma or ductal carcinoma in situ and the adjacent cells may subsequently pro- gress to form another carcinoma. It is therefore essential to find prognostic indicators for recurrence in the morphologically normal epithelium. Earlier studies have revealed that patients with loss of heterozygosity in their normal tissues are more likely to have a tumor recurrence than patients whose normal tissues are not genetically aberrant (Deng et al., 1996). In depth analysis of our aCGH data are underway to determine the gene loss or gains in breast tumors. Hence, it is necessary to identify patients who would be at risk of recurrence in the adjacent tissues, so as to benefit from the more aggressive local therapy or counseling about their higher risk for local failure. Therefore, in addition to histopathological analysis, other molecular targets such as telomere dysfunction and expression of telomere related genes should be used as an integrated strategy to classify the tissues adjacent to tumor tissues as normal.

Although histopathological grading is an important factor for the risk assessment in patients with breast cancer, it could be subjective and a large proportion of tumors are characterized as intermediate-grade tumors, making the best treatment modality inaccurate. An association was observed between the telomere dysfunction and the grade of differentiation of breast cancer in this study. The data presented in this study show that telomere dysfunction when used as an adjunct to conventional histopathological assessment might provide clinically relevant information with respect to 
the degree of malignancy. Therefore, telomere dysfunction could also be used as a marker for the aggressiveness of the tumors.

\section{ACKNOWLEDGMENTS}

The authors thank the co-operation of Dr. Rajiv Singh and the technical staff of the Department of Pathology, National University Hospital, Singapore.

\section{REFERENCES}

Banerjee B, Sharma S, Hegde S, Hande MP. 2008. Analysis of telomere damage by fluorescence in situ hybridisation on micronuclei in lymphocytes of breast carcinoma patients after radiotherapy. Breast Cancer Res Treat 107:25-31.

Bednarek AK, Sahin A, Brenner AJ, Johnston DA, Aldaz CM. 1997. Analysis of telomerase activity levels in breast cancer: Positive detection at the in situ breast carcinoma stage. Clin Cancer Res 3:11-16.

Bignold LP. 2007. Variation, "evolution”, immortality and genetic instabilities in tumour cells. Cancer Lett 253:155-169.

Bilaud T, Koering CE, Binet-Brasselet E, Ancelin K, Pollice A, Gasser SM, Gilson E. 1996. The telobox, a Myb-related telomeric DNA binding motif found in proteins from yeast, plants and human. Nucleic Acids Res 24:1294-1303.

Bilaud T, Brun C, Ancelin K, Koering CE, Laroche T, Gilson E. 1997. Telomeric localization of TRF2, a novel human telobox protein. Nat Genet 17:236-239.

Broccoli D, Smogorzewska A, Chong L, de Lange T. 1997. Human telomeres contain two distinct Myb-related proteins, TRF1 and TRF2. Nat Genet 17:231-235.

Campisi J, Kim SH, Lim CS, Rubio M. 2001. Cellular senescence, cancer and aging: The telomere connection. Exp Gerontol 36:1619-1637.

Chia KS, Lee JJ, Wong JL, Gao W, Lee HP, Shanmugaratnam K. 2002. Cancer incidence in Singapore, 1998 to 1999. Ann Acad Med Singapore 31:745-750.

Chin K, de Solorzano CO, Knowles D, Jones A, Chou W, Rodriguez EG, Kuo WL, Ljung BM, Chew K, Myambo K, Miranda M, Krig S, Garbe J, Stampfer M, Yaswen P, Gray JW, Lockett SJ. 2004. In situ analyses of genome instability in breast cancer. Nat Genet 36:984-988

Christov K, Milev A, Todorov V. 1989. DNA aneuploidy and cell proliferation in breast tumors. Cancer 64:673-679.

Clark GM, Osborne CK, Levitt D, Wu F, Kim NW. 1997. Telomerase activity and survival of patients with node-positive breast cancer. J Natl Cancer Inst 89:1874-1881.

Dalton LW, Pinder SE, Elston CE, Ellis IO, Page DL, Dupont WD, Blamey RW. 2000. Histologic grading of breast cancer: Linkage of patient outcome with level of pathologist agreement. Mod Pathol 13:730-735.

Deng G, Lu Y, Zlotnikov G, Thor AD, Smith HS. 1996. Loss of heterozygosity in normal tissue adjacent to breast carcinomas. Science 274:2057-2059.

Donigian JR, de Lange T. 2007. The role of the poly (ADP-ribose) polymerase tankyrase 1 in telomere length control by the TRF 1 component of the shelterin complex. J Biol Chem 282:2266222667.

Dunnwald LK, Rossing MA, Li CI. 2007. Hormone receptor status, tumor characteristics, and prognosis: A prospective cohort of breast cancer patients. Breast Cancer Res 9:R6.

Ellsworth RE, Hooke JA, Love B, Kane JL, Patney HL, Ellsworth DL, Shriver CD. 2008. Correlation of levels and patterns of genomic instability with histological grading of invasive breast tumors. Breast Cancer Res Treat 107:259-265.

Gelmini S, Poggesi M, Distante V, Bianchi S, Simi, L, Luconi M, Raggi CC, Cataliotti ,L, Pazzagli M, Orlando C. 2004. Tankyrase, a positive regulator of telomere elongation, is over expressed in human breast cancer. Cancer Lett 216:81-87.

Griffith JK, Bryant JE, Fordyce CA, Gilliland FD, Joste NE, Moyzis RK. 1999. Reduced telomere DNA content is correlated with genomic instability and metastasis in invasive human breast carcinoma. Breast Cancer Res Treat 54:59-64.

Hanahan D, Weinberg RA. 2000. The hallmarks of cancer. Cell 100:57-70.
Hande MP, Samper E, Lansdorp P, Blasco MA. 1999. Telomere length dynamics and chromosomal instability in cells derived from telomerase null mice. J Cell Biol 144:589-601.

Hayes DF, Isaacs C, Stearns V. 2001. Prognostic factors in breast cancer: Current and new predictors of metastasis. J Mammary Gland Biol Neoplasia 6:375-392.

Hines WC, Fajardo AM, Joste NE, Bisoffi M, Griffith JK. 2005. Quantitative and spatial measurements of telomerase reverse transcriptase expression within normal and malignant human breast tissues. Mol Cancer Res 3:503-509.

Jin Y, Stewenius Y, Lindgren D, Frigyesi A, Calcagnile O, Jonson T, Edqvist A, Larsson ,N, Lundberg LM, Chebil G, Liedberg F, Gudjonsson S, Mansson W, Hoglund M, Gisselsson D. 2007. Distinct mitotic segregation errors mediate chromosomal instability in aggressive urothelial cancers. Clin Cancer Res 13:17031712 .

Kirkpatrick KL, Clark G, Ghilchick M, Newbold RF, Mokbel K. 2003a. hTERT mRNA expression correlates with telomerase activity in human breast cancer. Eur J Surg Oncol 29:321-326.

Kirkpatrick KL, Ogunkolade W, Elkak AE, Bustin S, Jenkins P, Ghilchick M, Newbold RF, Mokbel K. 2003b. hTERT expression in human breast cancer and non-cancerous breast tissue: Correlation with tumour stage and c-Myc expression. Breast Cancer Res Treat 77:277-284

Kronenwett U, Ploner A, Zetterberg A, Bergh J, Hall P, Auer G, Pawitan Y. 2006. Genomic instability and prognosis in breast carcinomas. Cancer Epidemiol Biomarkers Prev 15:1630-1635.

Lengauer C. 2001. How do tumors make ends meet? Proc Natl Acad Sci USA 98:12331-12333.

Liu D, O'Connor MS, Qin J, Songyang Z. 2004a. Telosome, a mammalian telomere-associated complex formed by multiple telomeric proteins. J Biol Chem 279:51338-51342.

Liu D, Safari A, O'Connor MS, Chan DW, Laegeler A, Qin J, Songyang Z. 2004b. PTOP interacts with POT1 and regulates its localization to telomeres. Nat Cell Biol 6:673-680.

Lo AW, Sabatier L, Fouladi B, Pottier G, Ricoul M, Murnane JP. 2002. DNA amplification by breakage/fusion/bridge cycles initiated by spontaneous telomere loss in a human cancer cell line. Neoplasia 4:531-538.

Loeb LA. 2001. A mutator phenotype in cancer. Cancer Res 61:3230-3239.

McPherson JP, Hande MP, Poonepalli A, Lemmers B, Zablocki E, Migon E, Shehabeldin A, Porras A, Karaskova J, Vukovic B, Squire J, Hakem R. 2006. A role for Brca1 in chromosome end maintenance. Hum Mol Genet 15:831-838.

Meeker AK, Argani P. 2004. Telomere shortening occurs early during breast tumorigenesis: A cause of chromosome destabilization underlying malignant transformation? J Mammary Gland Biol Neoplasia 9:285-296.

Mokbel K, Parris CN, Ghilchik M, Williams G, Newbold RF. 1999. The association between telomerase, histopathological parameters, and KI-67 expression in breast cancer. Am J Surg 178:6972.

Mokbel KM, Parris CN, Ghilchik M, Amerasinghe CN, Newbold RF. 2000. Telomerase activity and lymphovascular invasion in breast cancer. Eur J Surg Oncol 26:30-33.

Murnane JP, Sabatier L. 2004. Chromosome rearrangements resulting from telomere dysfunction and their role in cancer. Bioessays 26:1164-1174.

Odagiri E, Kanada N, Jibiki K, Demura R, Aikawa E, Demura H. 1994. Reduction of telomeric length and c-erbB-2 gene amplification in human breast cancer, fibroadenoma, and gynecomastia. Relationship to histologic grade and clinical parameters. Cancer 73:2978-2984.

O'Hagan RC, Chang S, Maser RS, Mohan R, Artandi SE, Chin L, DePinho RA. 2002. Telomere dysfunction provokes regional amplification and deletion in cancer genomes. Cancer Cell 2:149155.

Raptis S, Bapat B. 2006. Genetic instability in human tumors. EXS 96:303-320.

Rha SY, Park KH, Kim TS, Yoo NC, Yang WI, Roh JK, Min JS, Lee KS, Kim BS, Choi JH, Lim HY, Chung HC. 1999. Changes of telomerase and telomere lengths in paired normal and cancer tissues of breast. Int J Oncol 15:839-845.

Roos G, Nilsson P, Cajander S, Nielsen NH, Arnerlov C, Landberg G. 1998. Telomerase activity in relation to p53 status and clinicopathological parameters in breast cancer. Int J Cancer 79:343-348.

Ruxton GD. 2006. The unequal variance t-test is an underused alternative to Student's t-test and the Mann-Whitney U test. Behav Ecol 17:688-690. 
Sabatier L, Ricoul M, Pottier G, Murnane JP. 2005. The loss of a single telomere can result in instability of multiple chromosomes in a human tumor cell line. Mol Cancer Res 3:139-150.

Saito K, Yagihashi A, Nasu S, Izawa Y, Nakamura M, Kobayashi D, Tsuji N, Watanabe N. 2002. Gene expression for suppressors of telomerase activity (telomeric-repeat binding factors) in breast cancer. Jpn J Cancer Res 93:253-258.

Salhab M, Jiang WG, Newbold RF, Mokbel K. 2008. The expression of gene transcripts of telomere-associated genes in human breast cancer: Correlation with clinico-pathological parameters and clinical outcome. Breast Cancer Res Treat 109:35-46.
Shpitz B, Zimlichman S, Zemer R, Bomstein Y, Zehavi T, Liverant S, Bernehim J, Kaufman Z, Klein E, Shapira Y, Klein A. 1999. Telomerase activity in ductal carcinoma in situ of the breast. Breast Cancer Res Treat 58:65-69.

Smith S, Giriat I, Schmitt A, de Lange T. 1998. Tankyrase, a poly (ADPribose) polymerase at human telomeres. Science 282:1484-1487.

Smogorzewska A, de Lange T. 2004. Regulation of telomerase by telomeric proteins. Annu Rev Biochem 73:177-208.

Stewenius Y, Jin Y, Ora I, de Kraker J, Bras J, Frigyesi A, Alumets J, Sandstedt B, Meeker AK, Gisselsson D. 2007. Defective chromosome segregation and telomere dysfunction in aggressive Wilms' tumors. Clin Cancer Res 13:6593-6602. 